\title{
Size-Dependent Stability of a Cantilevered Piezoelectrically Actuated Micropipe Conveying Fluid
}

\author{
Li Yun-dong \\ School of mathematics and statistics, Sichuan University of Science \& Engineering, Zigong 643000, China. \\ Sichuan Province University Key Laboratory of Bridge Non-destruction Detecting and Engineering Computing, \\ Zigong 643000, China. E-mail: lyd1114@126.com
}

\author{
Cheng Feng \\ School of mathematics and statistics, Sichuan University of Science \& Engineering, Zigong 643000, China.
}

\begin{abstract}
Wen Huabin
Mechanical Engineering College, Sichuan University of Science \& Engineering, Zigong 643000, China.
\end{abstract}

\section{(Received 20 April 2020; accepted 17 October 2020)}

Size-dependent effects of a cantilevered piezoelectrically actuated micropipe conveying fluid are investigated. Based on the modified strain gradient beam theory, the model of system is obtained using Hamilton's principle. The motion equation is discretized into ordinary differential equations by Generalized Differential Quadrature Method (GDQM). A stability analysis of the system is completed through eigenvalue analysis. Numerical results show the effect of geometrical shape size, and length scale parameters on critical flow velocity, and critical voltage. Results prove that the modified strain gradient theory (MSGT) has a higher critical flow velocity and critical voltage than predicted by modified couple stress theory (MCST) and classical theory (CT).

\section{INTRODUCTION}

Pipe conveying fluid is widely used in important components of some engineering machinery. Since the middle of the last century, various vibration analyses of pipe conveying fluid have been performed by many scholars. Interested readers can refer to monographs ${ }^{1}$ and the review's paper. ${ }^{2}$ Compared with the macro-scale pipes conveying fluid, micro-scale pipes conveying fluid are often used to make microreactors, ${ }^{3}$ current-carrying devices, ${ }^{4}$ and microsensors. ${ }^{5}$ It is of great practical significance to study the vibration characteristics of micro-scale pipes conveying fluid.

Scholars have shown in the past decades that the micro-scale structures have size-dependent phenomena. Lam et al. ${ }^{6}$ developed a modified set of second-order deformation metrics, the dilatation gradient vector, the deviatoric stretch gradient tensor, and the rotation gradient tensor, and derived the corresponding work-conjugate stress metrics as the basic strain and stress measures for a strain gradient theory for elasticity, i.e., the modified strain gradient theory. Tang and Alici ${ }^{7,8}$ presented a method to obtain the length-scale factors for silicon cantilevers by using the experimental data provided by the microand nanoindentation measurements. The natural frequency and deflection models for micro-and nano-sized silicon cantilevers are provided to incorporate the effect of the length-scale factors. Dehrouyeh-Semnani ${ }^{9}$ investigated the static bending of thin plane-strain microbeam based on modified couple stress and strain gradient elasticity constitutive beam models. The modified couple stress and strain gradient elasticity of the Euler-Bernoulli beam models overestimate the bending rigidity of the micro-cantilever when the size effect is significant.
The size effect in the structural behavior of systems can also be found in some literature ${ }^{10-15}$ based on the modified strain gradient theory.

A few research results have been obtained for the microscale pipes conveying fluid on the microscale theory of some of the above documents. Several achievements have been made in the research of micro-scale pipe conveying fluid in the last ten years. Rinaldi et al. ${ }^{16}$ presented the first set of results on the effects of miniaturization on stability, damping, and frequency shifts in straight micromachined pipes containing an internal flow. Wang ${ }^{17}$ established a theoretical model for fluidconveying microtubes using the modified couple stress theory and explored the effects of the internal material length scale parameter on the natural frequencies and the critical flow velocities. Xia and Wang ${ }^{18}$ developed a microstructure-dependent Timoshenko model for the microscale pipes containing internal fluid using modified couple stress theory. Yin et al. ${ }^{19}$ proposed a microstructure-dependent Bernoulli-Euler model for microscale pipes containing internal fluid by using the strain gradient and analyzed the vibration and stability of microscale simply supported pipe. Yang et al. ${ }^{20}$ demonstrated the microstructure-dependent size effect. The post-buckling configurations, nonlinear frequency, and response were presented.

Hosseini et al. ${ }^{21}$ investigated the size-dependent stability analysis of the cantilever micropipes conveying fluid and examined the effect of length scale parameter, outside diameter, aspect ratio, and the type of microstructure model on the mechanical behaviors of micropipes. Deng et al. ${ }^{22}$ examined the free vibration and stability of multi-span FGM micropipe conveying fluid. A hybrid method, which com- 
bines reverberation-ray matrix and wave propagation, is developed in consideration of the natural frequencies of the system. Ghazavi et al. ${ }^{23}$ analyzed the in-plane and out-of-plane vibrations and stability of curved microtubes. The size effects were also studied on the basis of strain gradient theory, and the results were compared with those obtained on the basis of couple stress and classical elasticity theory. On the other hand, the application of piezoelectric materials in engineering structures has drawn increasing attention. Rezazadeh et al. ${ }^{24}$ illustrated the effectiveness of a pair of surface-bonded piezoelectric patches to enhance controlling the pull-in voltage of fixed-fixed and cantilever micro-electro-mechanical (MEM) actuators subjected to residual stress, fringing field, and axial stress effects. Abbasnejad et al. ${ }^{25}$ investigated the effect of applying piezoelectric layers on the stability of the fluid conveying micropipes. The effect of piezoelectric voltage on frequencies and critical flow velocities was thoroughly discussed using eigenfrequency branches. Hosseini et al. ${ }^{26}$ studied the forced vibrations of double piezoelectric functionally graded material micropipes conveying fluid carrying a moving load based on the flexoelectricity theory and modified couple stress theory. Hosseini et al. ${ }^{27}$ also demonstrated the divergence and flutter instability of a cantilever piezoelectric carbon nanotube and discussed the effects of different parameters such as piezoelectric voltage, surface residual stress, surface elasticity constant, and surface piezoelectric constant, on the critical flutter velocity of the CNT.

The classical continuum theory of elasticity shows the uncertainly in describing the mechanical behavior of the system considering the study of microscale pipe conveying fluid. Theories of higher order, such as, modified couple stress theory and strain gradient theory, can effectively describe the mechanical behavior of micro-scale structures, as presented by the aforementioned literature. ${ }^{17,18,20}$ However, the discussion of the piezoelectrically actuated microbeams ${ }^{28}$ and micropipe conveying fluid ${ }^{25}$ did not involve the influence of the size effect and only established a model using classical theory. The authors believe that the dynamic model established by this method is insufficient to reflect the mechanical behavior of piezoelectrically actuated micropipe conveying pipe.

The goal of this paper is to investigate the size-dependent effect of piezoelectrically actuated micropipe conveying fluid by using modified strain gradient theory. The governing equation of motion of the system is obtained using strain energy together with Hamilton's principle. The Generalized Differential Quadrature Method (GDQM) is used to calculate the natural frequency and flutter critical flow velocity and voltage of micro-scale pipe conveying fluid, and the effect of geometrical parameters is discussed.

\section{MATHEMATICAL MODELLING}

The modified strain gradient elasticity theory for micropipe conveying fluid is presented in the literature. ${ }^{19}$ Interested readers can refer to the literature ${ }^{19}$ for additional details on this theory. The basic equations associated with the modified strain gradient and the couple stress theories will be omitted. The size effect is considered for the micropipe and the piezoelectric layer. The Knudsen number (the ratio of the molecular mean free path length of fluid to the inner diameter of micropipe) in the current problem is sufficiently small due to the influence of

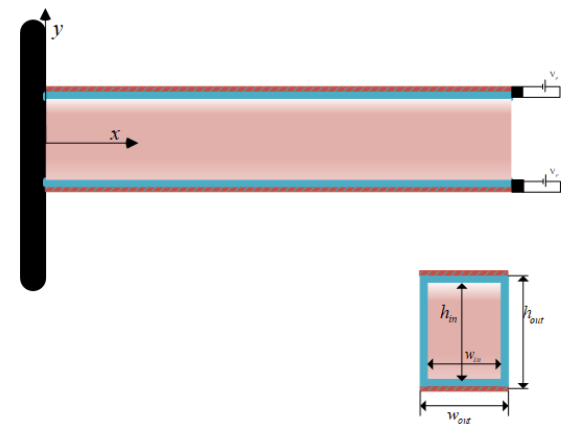

Figure 1. Schematic views of the piezoelectrically actuated micro-pipe conveying fluid.

fluid flow based on the classical equations of fluid dynamics. The assumptions made in this paper are as follows: (1) The fluid in the micropipes is ideal, that is, the inviscid and incompressible fluid. (2) The fluid velocity in the pipe is constant. (3) The length of the pipe is far greater than the diameter of the pipe, and the materials of the pipes are the same and uniform. (4) Only the in-plane vibration of the pipe is considered. (5) The Poisson's effect was neglected.

A cantilevered piezoelectrically actuated micropipe conveying fluid is shown in Fig. 1. A pipe of length $L$, pipe density $\rho_{p}$, outer layer width $w_{\text {out }}$, and inner layer width $w_{\text {in }}$, outer layer height $h_{\text {out }}$, inner layer height $h_{\text {in }}$ are considered isotropic with a pair of piezoelectric layers bonded on its surfaces, each piezoelectric layer has a thickness $h_{p}$, and the width $w_{p}$ of each piezoelectric layer is equal to the outer layer width $w_{\text {out }}$, that is, $w_{p}=w_{\text {out }}$. The fluid in the pipe is incompressible fluid with density $\rho_{f}$ and axial flow velocity $U$. The piezoelectric layered cantilever pipe is considered to be an Euler-Bernoulli type. $x$ and $y$ represent the axial and transverse directions, respectively; the transverse one, in the y-direction, is represented by $w(x, t)$.

On the basis of the modified strain gradient theory, ${ }^{29}$ the potential energy of pipe includes the following terms ${ }^{21}$

$$
U_{b}=\frac{1}{2} \int_{0}^{L}\left(S_{b} \cdot\left(\frac{\partial^{2} w}{\partial x^{2}}\right)^{2}+K_{b} \cdot\left(\frac{\partial^{3} w(x, t)}{\partial x^{3}}\right)^{2}\right) d x
$$

where

$$
\begin{gathered}
K_{b}=I_{b}\left(2 G_{b} l_{0}^{2}+\frac{4}{5} G_{b} l_{1}^{2}\right) ; \\
S_{b}=E_{b} I_{b}+2 G_{b} A_{b} l_{0}^{2}+\frac{8}{15} G_{b} A_{b} l_{1}^{2}+G_{b} A_{b} l_{2}^{2} ; \\
A_{b}=h_{\text {out }} w_{\text {out }}-h_{\text {in }} w_{\text {in }}, I_{b}=\frac{w_{\text {out }} h_{\text {out }}^{3}}{12}-\frac{w_{\text {in }} h_{\text {in }}^{3}}{12} ;
\end{gathered}
$$

in which, $E_{b}$ and $G_{b}$ are the elastic and shear modulus of the pipe in the classical elasticity theory, respectively. $l_{0}, l_{1}$, and $l_{2}$ denote the three independent material length scale parameters related to the constitutive equations of the higher-order stresses. In the reference, ${ }^{21}$ material scale parameters $l_{0}, l_{1}$, and $l_{2}$ are independent material length scale parameters respectively associated with dilatation, deviatoric stretch, and rotation gradients. The length scale parameters in this paper do not denote real material length scale parameters. So, the value of the material length scale parameters is just an arbitrary assumption.

Applying a voltage $V_{p}$ on the piezoelectric layers located on the micro-pipe surfaces, the piezoelectric voltage will lead to a 
follower force as provided below: ${ }^{24}$

$$
F_{p}=-2 w_{\text {out }} \bar{e}_{31} V_{p}
$$

where $\bar{e}_{31}$ the equivalent piezoelectric coefficient.

Considering the piezoelectrically exciting force as the follower force, the potential energy related to the piezoelectric layers can be written as: ${ }^{25}$

$$
\Pi_{F x}=\frac{1}{2} F_{p} \int_{0}^{L}\left(\frac{\partial w}{\partial x}\right)^{2} d x
$$

and

$$
\delta \Pi_{F y}=\left.F_{p} \frac{\partial w}{\partial x} \delta w\right|_{x=L} ;
$$

where $\Pi_{F_{x}}$ and $\Pi_{F_{y}}$ denote the work respectively conducted by the $x$ - and $y$-components of the follower force $F_{p}$. Current authors indicate that equation (6) does not appear in the. ${ }^{25}$ Some literature works reveal that actuated force $F_{p}$ is not included in the equations of the boundary conditions. However, the authors use the same method to re-deduce the governing equations and the boundary conditions. The process of derivation shows that Eq. (6) cannot be omitted.

The potential energy of the piezoelectric layer includes the following terms ${ }^{21}$ :

$$
U_{p}=\frac{1}{2} \int_{0}^{L}\left(S_{p} \cdot\left(\frac{\partial^{2} w}{\partial x^{2}}\right)^{2}+K_{p} \cdot\left(\frac{\partial^{3} w(x, t)}{\partial x^{3}}\right)^{2}\right) d x
$$

where

$$
\begin{gathered}
K_{p}=I_{p}\left(2 G_{p} l_{0}^{2}+\frac{4}{5} G_{p} l_{1}^{2}\right) \\
S_{p}=E_{p} I_{p}+2 G_{p} A_{p} l_{0}^{2}+\frac{8}{15} G_{p} A_{p} l_{1}^{2}+G_{p} A_{p} l_{2}^{2} \\
A_{p}=2 w_{p} h_{p}, I_{p}=\frac{2 w_{b} h_{p}}{3}\left(\frac{3 h_{\text {out }}^{2}}{4}+h_{p}^{2}+\frac{3}{2} h_{\text {out }} h_{p}\right) ;
\end{gathered}
$$

where $E_{p}$ and $G_{p}$ are the elastic and shear modulus of piezoelectric layer in the classical elasticity theory, respectively.

The kinetic energy includes the following terms

$$
\begin{aligned}
& T(t)=T_{b}+T_{p}+T_{f}= \\
& \frac{1}{2} \rho_{b} A_{b} \int_{0}^{L}\left(\frac{\partial w(x, t)}{\partial t}\right)^{2} d x+\frac{1}{2} \rho_{p} A_{p} \int_{0}^{L}\left(\frac{\partial w(x, t)}{\partial t}\right)^{2} d x+ \\
& \frac{1}{2} \rho_{f} A_{f} \int_{0}^{L}\left(\left(\frac{\partial w}{\partial t}+U \frac{\partial w}{\partial x}\right)^{2}\right) d x
\end{aligned}
$$

where $A_{f}=h_{i n} w_{i n}$.

The governing equation of the transverse motion can be obtained by the minimization of the Lagrangian using the variational principle:

$$
\int_{0}^{t}(\delta T-\delta \Pi) d t=\int_{t_{1}}^{t_{2}} M U\left(\dot{w}_{L}+U w_{L}^{\prime}\right) \delta w_{L} d t
$$

where

$$
\delta \Pi=\delta \Pi_{b}+\delta \Pi_{F_{x}}+\delta \Pi_{F_{y}}+\delta \Pi_{p} .
$$

Substituting expressions (1), (4), (5), (6), (7), and (10) into
Eq. (11) and using the integral transformation

$$
\begin{aligned}
& \delta \int_{t_{1}}^{t_{2}}(T-U) d t-\int_{t_{1}}^{t_{2}} M U_{0}\left(\dot{w}_{L}+U w^{\prime}{ }_{L}\right) \delta w_{L} d t \\
& =-\left(\rho_{b} A_{b}+\rho_{p} A_{p}+m_{f}\right) \int_{t_{1}}^{t_{2}} \int_{0}^{L} \ddot{w} d x d t+ \\
& \left.\left(\rho_{b} A_{b}+\rho_{p} A_{p}+m_{f}\right) \int_{0}^{L} \dot{w} \delta w\right|_{t_{1}} ^{t_{2}} d x+ \\
& -m_{f} U_{0}^{2} \int_{t_{1}}^{t_{2}} \int_{0}^{L} w^{\prime \prime} d x d t+\left.m_{f} U_{0}^{2} \int_{t_{1}}^{t_{2}} w^{\prime} \delta w\right|_{0} ^{L} d t+ \\
& \left.m_{f} U_{0} \int_{0}^{L} w^{\prime} \delta w\right|_{t_{2}} ^{t_{2}} d x+\left.m_{f} U_{0} \int_{t_{1}}^{t_{2}} \dot{w} \delta w\right|_{0} ^{L} \\
& -2 m_{f} U_{0} \int_{t_{1}}^{t_{2}} \int_{0}^{L} \dot{w}^{\prime} \delta w d x d t-\left.\left(S_{p}+S_{b}\right) \int_{t_{1}}^{t_{2}} w^{\prime \prime} \delta w^{\prime}\right|_{0} ^{L} d t \\
& +\left.\left(S_{p}+S_{b}\right) \int_{t_{1}}^{t_{2}} w^{\prime \prime \prime} \delta w\right|_{0} ^{L} d t- \\
& \left(S_{p}+S_{b}\right) \int_{t_{1}}^{t_{2}} \int_{0}^{L} w^{\prime \prime \prime \prime} \delta w d x d t- \\
& \left.F_{p} \int_{t_{1}}^{t_{2}} w^{\prime} \delta w\right|_{0} ^{L} d t+F_{p} \int_{t_{1}}^{t_{2}} \int_{0}^{L} w^{\prime \prime} \delta w d x d t- \\
& \left.\left(K_{p}+K_{b}\right) \int_{t_{1}}^{t_{2}} w^{\prime \prime \prime} \delta w^{\prime \prime}\right|_{0} ^{L} d t+ \\
& \left.\left(K_{p}+K_{b}\right) \int_{t_{1}}^{t_{2}} w^{\prime \prime \prime \prime} \delta w^{\prime}\right|_{0} ^{L} d t- \\
& \left.\left(K_{p}+K_{b}\right) \int_{t_{1}}^{t_{2}} w^{\prime \prime \prime \prime \prime \prime} \delta w\right|_{0} ^{L} d t+ \\
& \left(K_{p}+K_{b}\right) \int_{t_{1}}^{t_{2}} \int_{0}^{L} w^{\prime \prime \prime \prime \prime \prime} \delta w d x d t- \\
& \int_{t_{1}}^{t_{2}} M U_{0}\left(\dot{w}_{L}+U_{0} w^{\prime}{ }_{L}\right) \delta w_{L} d t- \\
& F_{p} \int_{t_{1}}^{t_{2}} w^{\prime} \delta w_{L} d t=0 .
\end{aligned}
$$

The governing equation of motion is derived as follows:

$$
\begin{gathered}
\left(\rho_{p} A_{p}+\rho_{b} A_{b}+m_{f}\right) \frac{\partial^{2} w}{\partial t^{2}}+\left(S_{p}+S_{b}\right) \frac{\partial^{4} w}{\partial x^{4}}- \\
\left(K_{p}+K_{b}\right) \frac{\partial^{6} w}{\partial x^{6}}-F_{p} \frac{\partial^{2} w}{\partial x^{2}}+m_{f} U_{0}^{2} \frac{\partial^{2} w}{\partial x^{2}}+2 m_{f} U_{0} \frac{\partial^{2} w}{\partial x \partial t}=0 .
\end{gathered}
$$

The corresponding boundary conditions from Hamilton's method for cantilevered micro-pipe conveying fluid are written as follows

$$
\begin{aligned}
x=0: & {\left[\left(S_{b}+S_{p}\right) w^{\prime \prime \prime}-\left(K_{p}+K_{b}\right) w^{\prime \prime \prime \prime \prime}\right] \delta w=0 ; } \\
& {\left[-\left(S_{b}+S_{p}\right) w^{\prime \prime}+\left(K_{b}+K_{p}\right) w^{\prime \prime \prime \prime}\right] \delta w^{\prime}=0 ; } \\
& \left(K_{p}+K_{b}\right) w^{\prime \prime \prime} \delta w^{\prime \prime}=0 \\
x=L: & {\left[-\left(S_{b}+S_{p}\right) w^{\prime \prime \prime}+\left(K_{p}+K_{b}\right) w^{\prime \prime \prime \prime \prime}\right] \delta w=0 ; } \\
& {\left[\left(S_{b}+S_{p}\right) w^{\prime \prime}-\left(K_{b}+K_{p}\right) w^{\prime \prime \prime \prime}\right] \delta w^{\prime}=0 ; } \\
& \left(K_{p}+K_{b}\right) w^{\prime \prime \prime} \delta w^{\prime \prime}=0 .
\end{aligned}
$$

For a pipe with a cantilever, the classical boundary conditions at ends of pipe are as follows:

$$
\begin{aligned}
x=0 & : w=0, w^{\prime}=0 ; \\
x=L & :\left(S_{b}+S_{p}\right) w^{\prime \prime}-\left(K_{b}+K_{p}\right) w^{\prime \prime \prime \prime}=0 ; \\
& \quad-\left(S_{b}+S_{p}\right) w^{\prime \prime \prime}-\left(K_{p}+K_{b}\right) w^{\prime \prime \prime \prime \prime}=0 .
\end{aligned}
$$

Two possible boundary conditions at both ends are available for non-classical boundary conditions. One of the higher-order boundary conditions can be written as:

$$
\begin{aligned}
& x=0:\left(K_{p}+K_{b}\right) w^{\prime \prime \prime}=0 \text { or } w^{\prime \prime}=0 ; \\
& x=L:\left(K_{p}+K_{b}\right) w^{\prime \prime \prime}=0 \text { or } w^{\prime \prime}=0 .
\end{aligned}
$$

The boundary conditions in Eq. (17)-(18) can be reduced to the following four boundary conditions:

BC1:

$$
\begin{aligned}
& x=0: w=0, w^{\prime}=0, w^{\prime \prime}=0 \\
& x=L:-\left(S_{b}+S_{p}\right) w^{\prime \prime}+\left(K_{b}+K_{p}\right) w^{\prime \prime \prime \prime}=0 \\
& -\left(S_{b}+S_{p}\right) w^{\prime \prime \prime}+\left(K_{p}+K_{b}\right) w^{\prime \prime \prime \prime \prime}=0,\left(K_{p}+K_{b}\right) w^{\prime \prime \prime}=0 .
\end{aligned}
$$


$\mathrm{BC} 2$ :

$$
\begin{aligned}
x=0: & w=0, w^{\prime}=0, w^{\prime \prime}=0 ; \\
x=L: & -\left(S_{b}+S_{p}\right) w^{\prime \prime}+\left(K_{b}+K_{p}\right) w^{\prime \prime \prime \prime \prime}=0 ; \\
& -\left(S_{b}+S_{p}\right) w^{\prime \prime \prime}+\left(K_{p}+K_{b}\right) w^{\prime \prime \prime \prime \prime}=0, w^{\prime \prime}=0 .
\end{aligned}
$$

BC3:

$$
\begin{array}{cl}
x=0: & w=0, w^{\prime}=0, w^{\prime \prime \prime}=0 ; \\
x=L: & -\left(S_{b}+S_{p}\right) w^{\prime \prime}+\left(K_{b}+K_{p}\right) w^{\prime \prime \prime \prime}=0 ; \\
& -\left(S_{b}+S_{p}\right) w^{\prime \prime \prime}+\left(K_{p}+K_{b}\right) w^{\prime \prime \prime \prime \prime}=0 ; \\
& \left(K_{p}+K_{b}\right) w^{\prime \prime \prime}=0 .
\end{array}
$$

BC4:

$$
\begin{aligned}
x=0: & w=0, w^{\prime}=0, w^{\prime \prime \prime}=0 \\
x=L: & -\left(S_{b}+S_{p}\right) w^{\prime \prime}+\left(K_{b}+K_{p}\right) w^{\prime \prime \prime \prime}=0 \\
& -\left(S_{b}+S_{p}\right) w^{\prime \prime \prime}+\left(K_{p}+K_{b}\right) w^{\prime \prime \prime \prime \prime \prime}=0, w^{\prime \prime}=0 .
\end{aligned}
$$

References $^{30,31}$ indicate that parameter $\mu$ is a coefficient of the flow velocity profile representing the size effect of microflow. By introducing the parameter $\mu$ into the governing Eq. (14), one obtains:

$$
\begin{gathered}
\left(\rho_{p} A_{p}+\rho_{b} A_{b}+m_{f}\right) \frac{\partial^{2} w}{\partial t^{2}}+\left(S_{p}+S_{b}\right) \frac{\partial^{4} w}{\partial x^{4}}- \\
\left(K_{p}+K_{b}\right) \frac{\partial^{6} w}{\partial x^{6}}-F_{p} \frac{\partial^{2} w}{\partial x^{2}}+\mu m_{f} U_{0}^{2} \frac{\partial^{2} w}{\partial x^{2}}+2 m_{f} U_{0} \frac{\partial^{2} w}{\partial x \partial t}=0 .
\end{gathered}
$$

The flow velocity field of a Poiseuille-flow problem with a rectangular cross-section can be expressed as a Fourier sum $^{30,32}$ :

$v_{x}=\frac{4 h_{i n}^{2}}{\pi^{3}} \frac{\Delta p}{\eta L} \sum_{n=2 k+1}^{\infty} \frac{1}{n^{3}}\left[1-\frac{\cosh \left(n \pi \frac{y}{h_{i n}}\right)}{\cosh \left(n \pi \frac{w_{i n}}{2 h_{i n}}\right)}\right] \sin \left(n \pi \frac{z}{h_{i n}}\right) ;$

where $\Delta p$ is the pressure difference between the two ends of the pipe, and $\eta$ is the viscosity of the internal fluid. The parameter $\mu$ can be given by ${ }^{32}$ :

$$
\mu=\frac{A \int_{A} v_{x}^{2} d A}{\left(\int_{A} v_{x} d A\right)^{2}}
$$

\section{PROCEDURES OF SOLUTION}

The following dimensionless quantities are defined to simplyfy the Eq. (23):

$$
\begin{aligned}
w^{*} & =\frac{w}{L}, \quad \xi=\frac{x}{L}, \quad t^{*}=\sqrt{\frac{E_{p} I_{p}+E_{b} I_{b}}{\left(\rho_{p} A_{p}+\rho_{b} A_{b}+m_{f}\right) L^{4}}} t \\
\beta & =\frac{m_{f}}{\rho_{p} A_{p}+\rho_{b} A_{b}+m_{f}}, \quad S^{*}=\frac{S_{p}+S_{b}}{E_{p} I_{p}+E_{b} I_{b}} \\
K^{*} & =\frac{K_{p}+K_{b}}{E_{p} I_{p}+E_{b} I_{b}}, \quad \tilde{F}_{p}=\frac{F_{p} L^{2}}{E_{p} I_{p}+E_{b} I_{b}} \\
U & =U_{0} L \sqrt{\frac{M}{E_{p} I_{p}+E_{b} I_{b}}} .
\end{aligned}
$$

In dimensionless terms, disregarding the sign "*”, substituting (26) into Eq. (23), the dimensionless governing equation can be shown as follows:

$$
\begin{aligned}
& \frac{\partial^{2} w}{\partial t^{2}}+\tilde{S} \frac{\partial^{4} w}{\partial x^{4}}-\tilde{K} \frac{\partial^{6} w}{\partial x^{6}}-\tilde{F}_{p} \frac{\partial^{2} w}{\partial x^{2}}+\mu U^{2} \frac{\partial^{2} w}{\partial x^{2}} \\
& +2 \sqrt{\beta} U \frac{\partial^{2} w}{\partial x \partial t}=0 .
\end{aligned}
$$

The corresponding dimensionless boundaries include the following:

$\mathrm{BC} 1$ :

$$
\begin{aligned}
& \xi=0: w=0, w^{\prime}=0, w^{\prime \prime}=0 \\
& \xi=L:-\tilde{S} w^{\prime \prime}+\tilde{K} w^{\prime \prime \prime \prime}=0, w^{\prime \prime \prime \prime \prime}=0, w^{\prime \prime \prime}=0 .
\end{aligned}
$$

$\mathrm{BC} 2$ :

$$
\begin{aligned}
& \xi=0: w=0, w^{\prime}=0, w^{\prime \prime}=0 \\
& \xi=1: w^{\prime \prime \prime \prime}=0-\tilde{S} w^{\prime \prime \prime}+\tilde{K} w^{\prime \prime \prime \prime \prime}=0, w^{\prime \prime}=0 .
\end{aligned}
$$

BC3:

$$
\begin{aligned}
& \xi=0: w=0, w^{\prime}=0, w^{\prime \prime \prime}=0 \\
& \xi=1:-\tilde{S} w^{\prime \prime}+\tilde{K} w^{\prime \prime \prime \prime}=0, w^{\prime \prime \prime \prime \prime}=0, w^{\prime \prime \prime}=0 .
\end{aligned}
$$

BC4:

$$
\begin{aligned}
& \xi=0: w=0, w^{\prime}=0, w^{\prime \prime \prime}=0 ; \\
& \xi=1: w^{\prime \prime \prime \prime}=0-\tilde{S} w^{\prime \prime \prime}+\tilde{K} w^{\prime \prime \prime \prime \prime}=0, w^{\prime \prime}=0 .
\end{aligned}
$$

. The GDQM method is used to descretize the governing equation and boundary conditions to obtain the eigenvalues of micropipe conveying fluid. The GDQM can also be employed to solve the various vibration problem $\left.{ }^{33,34}\right)$.

The mesh is divided as follows

$$
x_{i}=\frac{1-\cos ((i-1) \pi /(N-1))}{2} \quad(i=1,2,, 3, \cdots, N-1, N) .
$$

On the basis of the algorithm of GDQM, the independent variable vector is

$$
\begin{gathered}
\{\mathbf{W}\}=\left\{W_{1}, W_{2}, W_{3}, W_{4}, \cdots, W_{N-1}, W_{N},\right. \\
\left.W_{N+1}, W_{N+4}\right\}^{T} \\
=\left\{w_{1}, w_{1}^{\prime}, w_{1}^{\prime \prime}, w_{2}, w_{3}, \cdots,\right. \\
\left.w_{N-1}, w_{N}, w_{N-1}^{\prime}, w_{N}^{\prime \prime}\right\}^{T} .
\end{gathered}
$$

Setting $\quad \mathbf{w}_{\mathbf{b}}=\left\{w_{1}, w_{1}^{\prime}, w_{1}^{\prime \prime}, w_{N}^{\prime \prime}, w_{N}^{\prime}, w_{N}\right\} \quad$ and $\mathbf{w}_{\mathrm{d}}=\left\{w_{2}, w_{3}, w_{4}, \cdots, w_{N-1}, w_{N}, w_{N+1}\right\}^{T}$, and discretizing Eqs. (27)-(31) by the GDQM, one obtains:

$$
\begin{aligned}
& \dot{w}_{i}+\tilde{S} \sum_{j=1}^{N+4} E_{i j}^{(4)} W_{j}-\tilde{K} \sum_{j=1}^{N+4} E_{i j}^{(6)} W_{j}+ \\
& \left(\tilde{F}_{p}+\mu U^{2}\right) \sum_{j=1}^{N+4} E_{i j}^{(2)} W_{j}+2 \sqrt{\beta} U \sum_{j=1}^{N+4} E_{i j}^{(1)} \dot{W}_{j}=0, \\
& i=2,3, \cdots N-2 .
\end{aligned}
$$


$\mathrm{BC} 1$ :

$$
\begin{gathered}
W_{1}=0, \quad \sum_{j=1}^{N+4} E_{1 j}^{(1)} W_{j}=0, \quad \sum_{j=1}^{N+4} E_{1 j}^{(2)} W_{j}=0 ; \\
-\tilde{S} \sum_{j=1}^{N+4} E_{N j}^{(2)} W_{j}+\tilde{K} \sum_{j=1}^{N+4} E_{N j}^{(4)} W_{j}=0 ; \\
\sum_{j=1}^{N+4} E_{N j}^{(5)} W_{j}=0, \quad \sum_{j=1}^{N+4} E_{N j}^{(3)} W_{j}=0 .
\end{gathered}
$$

BC2:

$$
\begin{gathered}
W_{1}=0, \quad \sum_{j=1}^{N+4} E_{1 j}^{(1)} W_{j}=0, \quad \sum_{j=1}^{N+4} E_{1 j}^{(2)} W_{j}=0 \\
\sum_{j=1}^{N+4} E_{N j}^{(4)} W_{j}=0, \quad \sum_{j=1}^{N+4} E_{N j}^{(2)} W_{j}=0 \\
-\tilde{S} \sum_{j=1}^{N+4} E_{N j}^{(3)} W_{j}+\tilde{K} \sum_{j=1}^{N+4} E_{N j}^{(5)} W_{j}=0 .
\end{gathered}
$$

BC3:

$$
\begin{aligned}
& W_{1}=0, \sum_{j=1}^{N+4} E_{1 j}^{(1)} W_{j}=0, \quad \sum_{j=1}^{N+4} E_{1 j}^{(3)} W_{j}=0 ; \\
&-\tilde{S} \sum_{j=1}^{N+4} E_{N j}^{(2)} W_{j}+\tilde{K} \sum_{j=1}^{N+4} E_{N j}^{(4)} W_{j}=0 ; \\
& \sum_{j=1}^{N+4} E_{N j}^{(5)} W_{j}=0, \quad \sum_{j=1}^{N+4} E_{N j}^{(3)} W_{j}=0 .
\end{aligned}
$$

BC4:

$$
\begin{gathered}
W_{1}=0, \quad \sum_{j=1}^{N+4} E_{1 j}^{(1)} W_{j}=0, \quad \sum_{j=1}^{N+4} E_{1 j}^{(3)} W_{j}=0 \\
\sum_{j=1}^{N+4} E_{N j}^{(4)} W_{j}=0, \quad \sum_{j=1}^{N+4} E_{N j}^{(2)} W_{j}=0 \\
-\tilde{S} \sum_{j=1}^{N+4} E_{N j}^{(3)} W_{j}+\tilde{K} \sum_{j=1}^{N+4} E_{N j}^{(5)} W_{j}=0 .
\end{gathered}
$$

In Eqs. (34)-(38), the coefficients $E_{i j}^{(r)}(r=1,2, \cdots, 6)$ are the weighting coefficient of the rth-order derivative at a grid point $\xi_{i}$ can be obtained from the literature $\left({ }^{34}\right)$. According to the literature, ${ }^{19}$ Eq.(34) and one of the boundary (35)-(38) can be rewritten in matrix form:

$$
\begin{gathered}
{\left[\begin{array}{cc}
{\left[K_{b b}\right]} & {\left[K_{b d}\right]} \\
{\left[K_{d b}\right]} & {\left[K_{d d}\right]}
\end{array}\right]\left\{\begin{array}{l}
\left\{w_{b}\right\} \\
\left\{w_{d}\right\}
\end{array}\right\}} \\
+\left[\begin{array}{cc}
{[0]} & {[0]} \\
{\left[G_{d b}\right]} & {\left[G_{d d}\right]}
\end{array}\right]\left\{\begin{array}{l}
\left\{\dot{w}_{b}\right\} \\
\left\{\dot{w}_{d}\right\}
\end{array}\right\} \\
+\left[\begin{array}{cc}
{[0]} & {[0]} \\
{\left[M_{d b}\right]} & {\left[M_{d d}\right]}
\end{array}\right]\left\{\begin{array}{l}
\left\{\ddot{w}_{b}\right\} \\
\left\{\ddot{w}_{d}\right\}
\end{array}\right\}=\left[\begin{array}{l}
{[0]} \\
{[0]}
\end{array}\right] .
\end{gathered}
$$

The first equation of Eq. (39) can be solved as follows:

$$
\left\{\mathrm{w}_{b}\right\}=-\left[K_{b b}\right]^{-1}\left[K_{b d}\right]\left\{w_{d}\right\}
$$

Table 1. The material contents of the microcantilever piezoelectrically actuated micro-pipe conveying fluid

\begin{tabular}{|l|c|c|}
\hline Parameters & $\begin{array}{c}\text { Microcantilever } \\
\text { pipe }\end{array}$ & $\begin{array}{c}\text { Piezoelectric } \\
\text { layer }\end{array}$ \\
\hline Length $(\mu \mathrm{m})$ & 800.0 & 800.0 \\
Young's modulus $(\mathrm{GPa})$ & 169.0 & 78.6 \\
Mass density $\left(\mathrm{kg} / \mathrm{m}^{3}\right)$ & 2331 & 7500 \\
Poisson's ratio & 0.06 & 0.3 \\
$e_{31}$ & & -9.29 \\
\hline
\end{tabular}

Substituting Eq. (40) into the second formula of Eq. (39), one obtains:

$$
[M]\left\{\ddot{w}_{d}\right\}+[C]\left\{\dot{w}_{d}\right\}+[K]\left[w_{d}\right]=0
$$

where

$$
\begin{array}{rlr}
M & = & -\left[\mathrm{M}_{d b}\right]\left[K_{b b}\right]^{-1}\left[K_{d b}\right]+\left[M_{d d}\right] ; \\
C & = & -\left[G_{d \mathrm{~b}}\right]\left[K_{b b}\right]^{-1}\left[K_{d b}\right]+\left[G_{d d}\right] ; \\
K= & -\left[K_{d b}\right]\left[K_{b b}\right]^{-1}\left[K_{d b}\right]+\left[K_{d d}\right] .
\end{array}
$$

To determine the nondimensional eigenvalues of the micropipe conveying fluid for a given piezoelectric voltage, the solution of Eq. (41) is assumed to be:

$$
w_{j}=A_{j} e^{\lambda_{j} t} .
$$

Substituting Eq. (43) into Eq. (41), the following relation is obtained:

$$
\left([\mathbf{M}] \lambda^{2}+[\mathbf{C}] \lambda+[\mathbf{K}]\right) A=0 .
$$

According to linear algebraic knowledge, the characteristic equation of the system can be obtained as follows:

$$
\left|\mathbf{M} \lambda^{2}+\mathbf{C} \lambda+\mathbf{K}\right|=0 .
$$

The imaginary component of the eigenvalue $\lambda$ is the dimensionless natural frequency of the system, and the real component of $\lambda$ is related to the damping, which can be used to identify the stability of the system.

\section{NUMERICAL RESULTS AND DISCUSSION}

To show the correction of the present algorithm, a comparison is made between the present method and Ref. ${ }^{21}$ Figure 2 shows the variation of first eigenvalues of micro-pipes predicted by CT, MSGT, and MCST with dimensionless fluid velocity $U$ for $D=100 \mu \mathrm{m}$, (a) imaginary part and (b) real part. In Fig. 2, the values of those parameters are the same as those in Ref. ${ }^{21}$ The results demonstrate a very good agreement with the numerical results obtained in Ref. ${ }^{21}$

The numerical results of the micropipe conveying fluid for cantilever piezoelectrically actuated micropipes based on MSGT are presented. The fluid density used in the simulation is $1000 \mathrm{~kg} / \mathrm{m}^{3}$, and the geometrical and material properties of the micro-pipe and the piezoelectric layers are listed in Table 1. The geometrical shape of the micropipes is made uniformly by letting $h_{\text {in }} / h_{\text {out }}=\alpha, w_{\text {in }} / w_{\text {out }}=\gamma$, and $L=800.0 \mu \mathrm{m}$, and the geometrical shape of the micro piezoelectric layer can be set by letting thickness $h_{p}=0.01 \mu \mathrm{m}$, and width $w_{p}=w_{\text {out }}$. All three material length scale parameters are assumed to be 


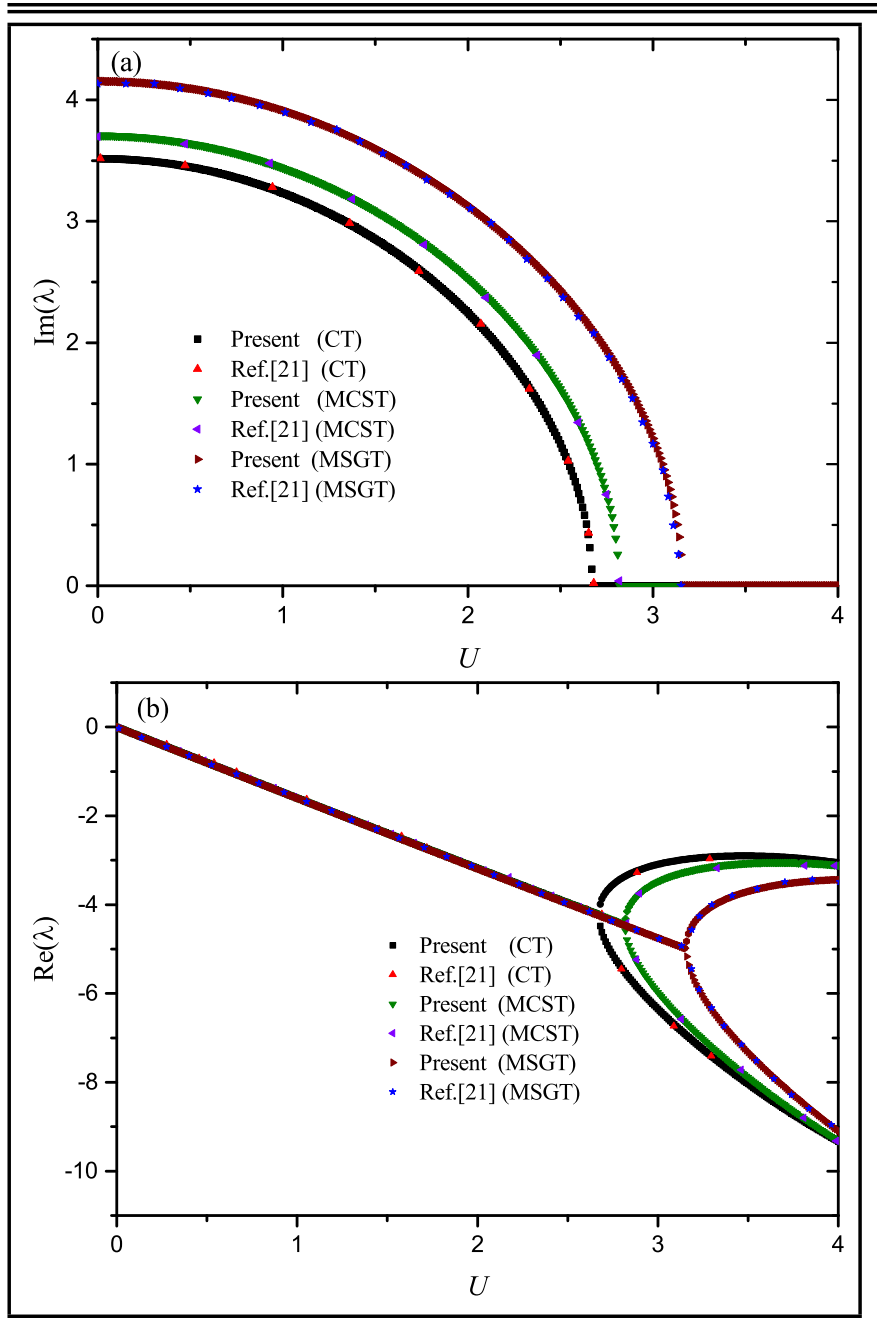

Figure 2. Comparison of first eigenvalues of micro-pipes got by CT, MCST and MSGT with dimensionless fluid velocity $U$ for $D=100 \mu m$, (a) imaginary part and (b) real part.

the same, that is, $\ell_{0}=\ell_{1}=\ell_{2}=\ell=17.6 \mu \mathrm{m}\left({ }^{29}\right)$. The influence of various boundary conditions on the vibration behavior of the system was initially studied. In Fig. 3, the real part of the third-order modal versus fluid velocity $U$ is shown under the following parameters $V=20.0 \mathrm{vol}, h_{\text {out }}=40.0 \mu \mathrm{m}$, and $h_{\text {in }}=38.0 \mu \mathrm{m}, w_{\text {out }}=50.0 \mu \mathrm{m}$. Figure 3 shows that, the unstable critical flow velocity is $U_{c r}=23.18$ in the present parameters, and the critical flow velocity under the four boundary conditions shows almost no difference. Therefore, the authors only considered using one of the four boundary conditions, that is, the first boundary condition, in the following analysis.

Figure 4 shows that considering the size effect of micro-flow and micro-structure, the coefficient $\mu$, which represents the effect of the flow velocity profile, is equal to 1.3746 with the same parameters in Fig. 3. The choice of $\mu=1.3746$ decreases the critical flow velocity and the unstable critical flow velocity is $U_{c r}=14.25$.

The system degenerates to a cantilever beam when the fluid velocity is zero. The critical dimensionless load (20.05) of the Beck problem for the cantilever beam is denoted as. ${ }^{35}$ Figure 5 shows the first three order imaginary and real parts of the eigenvalue versus the applied DC voltage in these parameters $U=0.0, h_{\text {out }}=30.0 \mu \mathrm{m}, h_{\text {in }}=20.0 \mu \mathrm{m}, w_{\text {in }}=48.0 \mu \mathrm{m}$, $w_{\text {out }}=50.0 \mu \mathrm{m}$. Figsures $5(\mathrm{a})$ and (b) respectively indicate the flutter instability is $V_{c r}=57.29$ and frequency

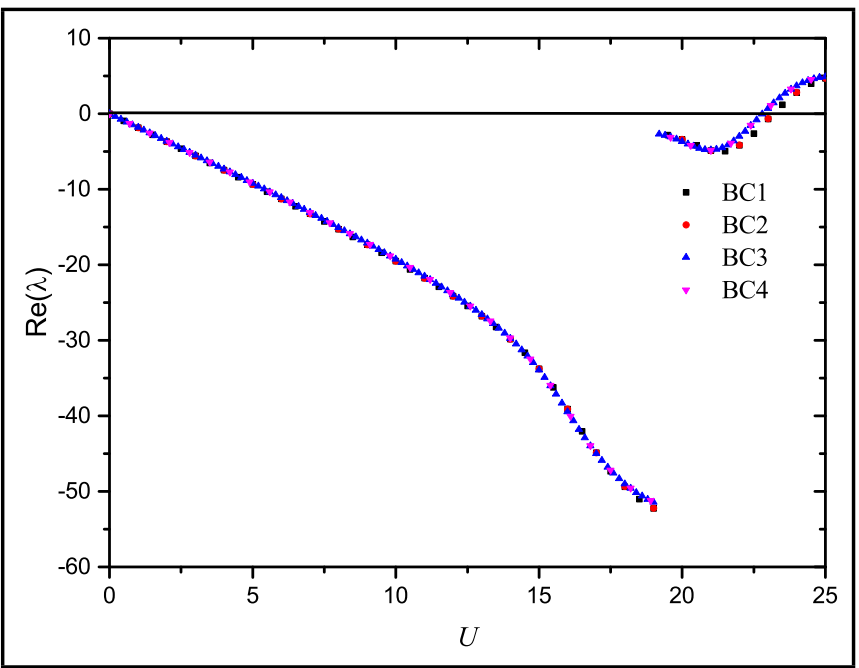

Figure 3. Real part of eigenvalue versus flow velocity under four kinds of boundary.

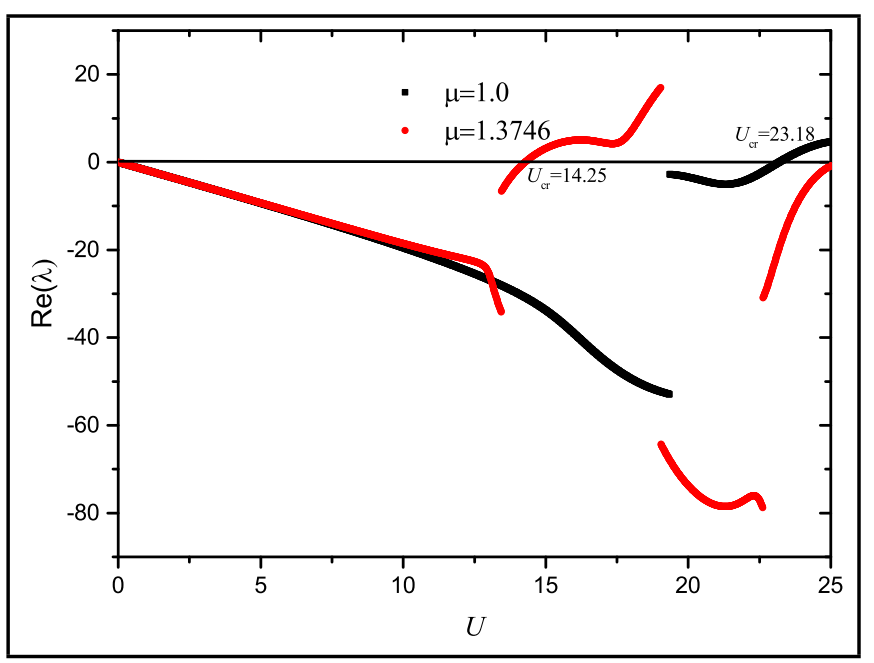

Figure 4. Real part of eigenvalue versus flow velocity under the coefficient $\mu=1.0$ and $\mu=1.3746$.

$\omega_{c r}=11.02$. The corresponding dimensionless piezoelectric force at this point is 20.07 , which is in good agreement with the foregoing description. However, the system does not undergo divergence instability, which is not in agreement with. ${ }^{28}$ The present authors believes that the possible reason that the Galerkin method's modal number is adopted by two order modal in. ${ }^{28}$ Figure 5 shows that the second flutter instability is obtained at $V_{c r}=365.16$ by increasing the piezoelectric voltage.

Figure 6 shows the evolution of the four lowest complex eigenfrequencies of the system with increasing flow velocity under the piezoelectric voltage $V=40.0 \mathrm{vol}, h_{\text {out }}=30.0 \mu \mathrm{m}$, $h_{\text {in }}=20.0 \mu \mathrm{m}, w_{\text {in }}=48.0 \mu \mathrm{m}, w_{\text {out }}=50.0 \mu \mathrm{m}$. In classical theory, Fig. 6(a) shows that the flutter unstable point of the system appears at the fluid velocity $U_{c r}=7.139$ and the unstable critical frequency $\omega_{c r}=26.452$ of the third-order mode. Fig. 6(b) reveals that the flutter unstable point of the system in the modified coupled stress theory appears at the fluid velocity $U_{c r}=13.728$ and the unstable critical frequency $\omega_{c r}=45.721$ of the third-order mode. In the modified strain gradient theory, as seen in Fig. 5(c), the flutter unstable point of the system appears at the fluid velocity $U_{c r}=22.156$ and third-order mode unstable critical frequency $\omega_{c r}=71.714$ of 


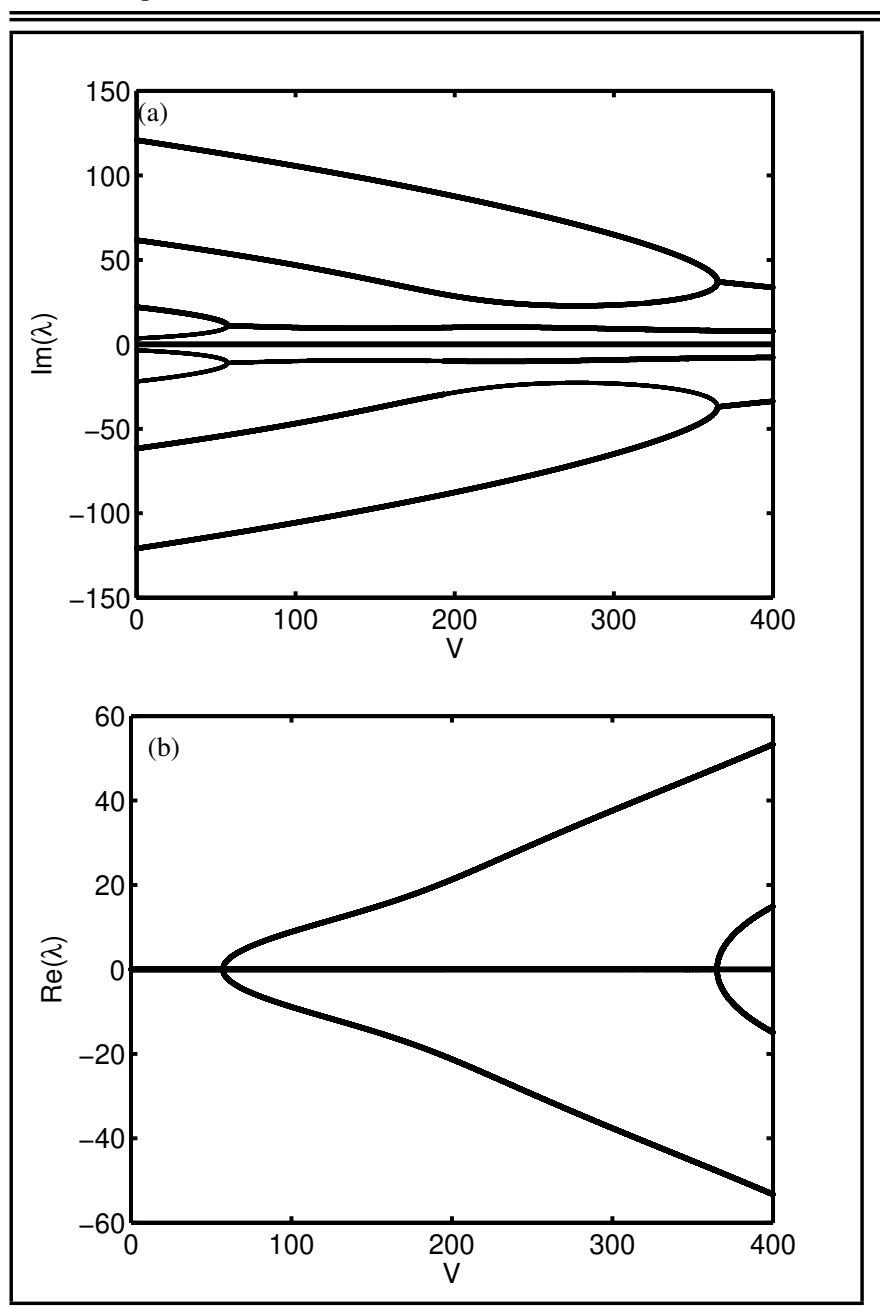

Figure 5. Flutter instabilities in the cantilever micropipe with $U=0.0, l_{0}=$ $l_{1}=l_{2}=0$ : (a) imaginary parts, (b) real parts.

the third-order mode. The value of the micro-scale parameters has a significant influence on the stability of micro pipe conveying fluid.

Figure 7 depicts the variation of flutter critical flow velocity and micro-pipe voltage with the parameter $\alpha$, which is equal to the ratio of parameter $h_{\text {in }} / h_{\text {out }}$ and the other parameter $h_{\text {in }}=20 \mu \mathrm{m}, w_{\text {out }}=50.0 \mu \mathrm{m}, \gamma=0.90, V=20.0$ vol. Figure 7(a) shows that the critical flow velocity $U_{c r}$ increases in the modified couple stress and strain gradient theory by raising the value $\alpha$, that is, the external geometric height parameter $h_{\text {out }}$. Figure 7(b) reveals the critical voltage $V_{c r}$ decreases under the special parameter $U=4.0$ by increasing the value of $\alpha$. In Figs. 7 and 8 the black, red, and blue lines denote the classical, modified couple stress, and modified strain gradient theories, respectively.

Figure 8 depicts the variation of the critical fluid velocities and critical voltage of micro-pipes concerning the parameters $\gamma$, which is equal to the parameter ratio $w_{\text {in }} / w_{\text {out }}$ and the other parameters $w_{\text {in }}=30.0 \mu \mathrm{m}, h_{\text {in }}=20 \mu \mathrm{m}, \alpha=0.95$. In Fig. 8(a), the critical flow velocity with voltage $V=20.0$ has a hysteretic phenomenon, as indicated in the study of Paidoussis $\left.{ }^{1}\right)$. In Fig. 8(b) the critical voltage $V_{c r}$ decreases with the increasing $\gamma$ parameter under flow velocity $U=3.50$.

Figure 9 shows the variation of critical fluid velocity and voltage of micro-pipes considering size-dependent effect $\ell$ and the other parameters $\alpha=0.95, \gamma=0.4$ under modified strain gradient theory. Fig. 9(a) shows the effect of the size-
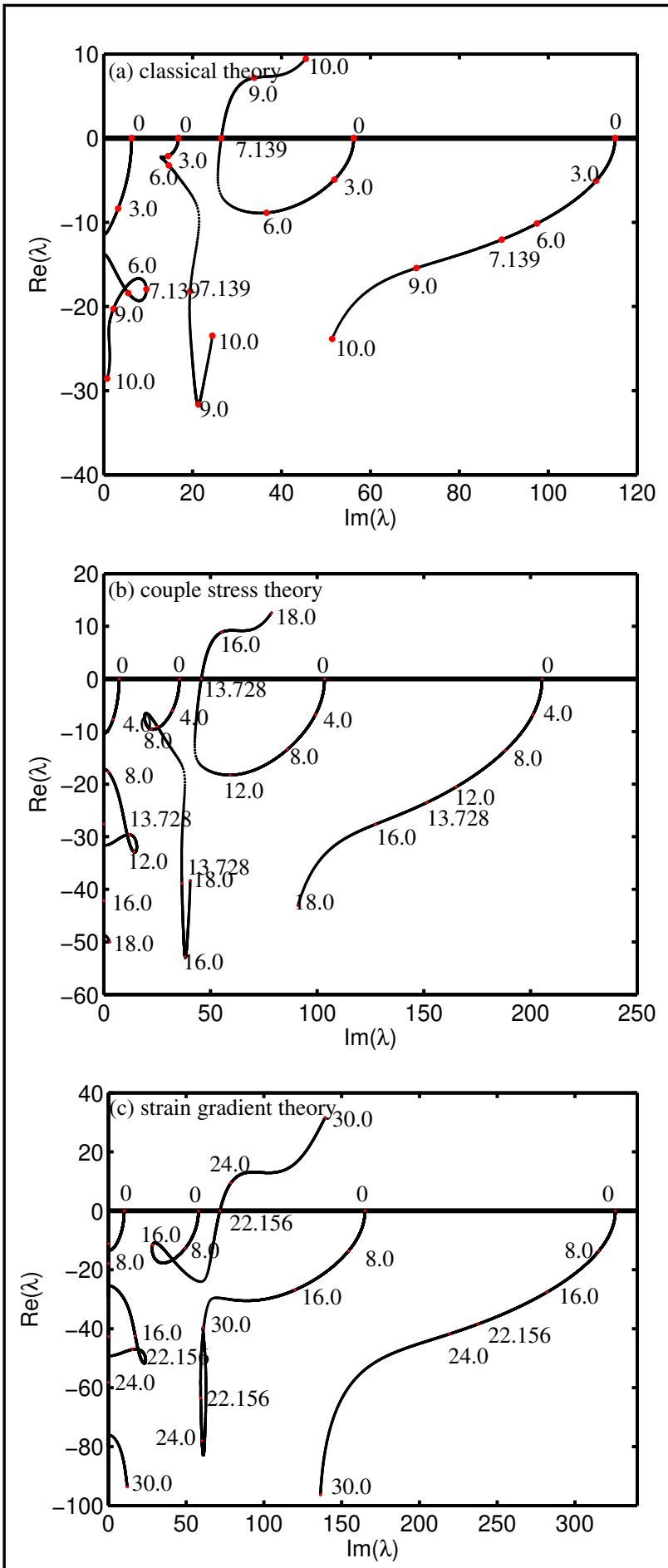

Figure 6. Dimensionless complex frequency of the lowest four modes of a cantilevered piezoelectrically actuated micropipe as a function of the dimensionless flow with (a) classic theory, (b) modified couple stress theory, and (c) modified strain gradient theory.

dependent effect $\ell$ on the flutter critical flow velocity with the parameter $V=5.0$. In Fig. 9(b) with the special parameter $U=3.50$ when the size-dependent effect $\ell$ increasing, the flutter critical voltage $V_{c r}$ also increases.

The instability region in the $(U, V)$ plane for a cantilevered pipe conveying fluid is shown in Fig. 10 considering the following parameters: $\alpha=0.95, \gamma=0.4, w_{\text {in }}=30.0 \mu \mathrm{m}$, and $h_{\text {in }}=20 \mu \mathrm{m}$. Three different theories are applied. This figure shows the parameter region in the $(U, V)$ plane is divided into two sub-regions according to different behaviors. The sta- 


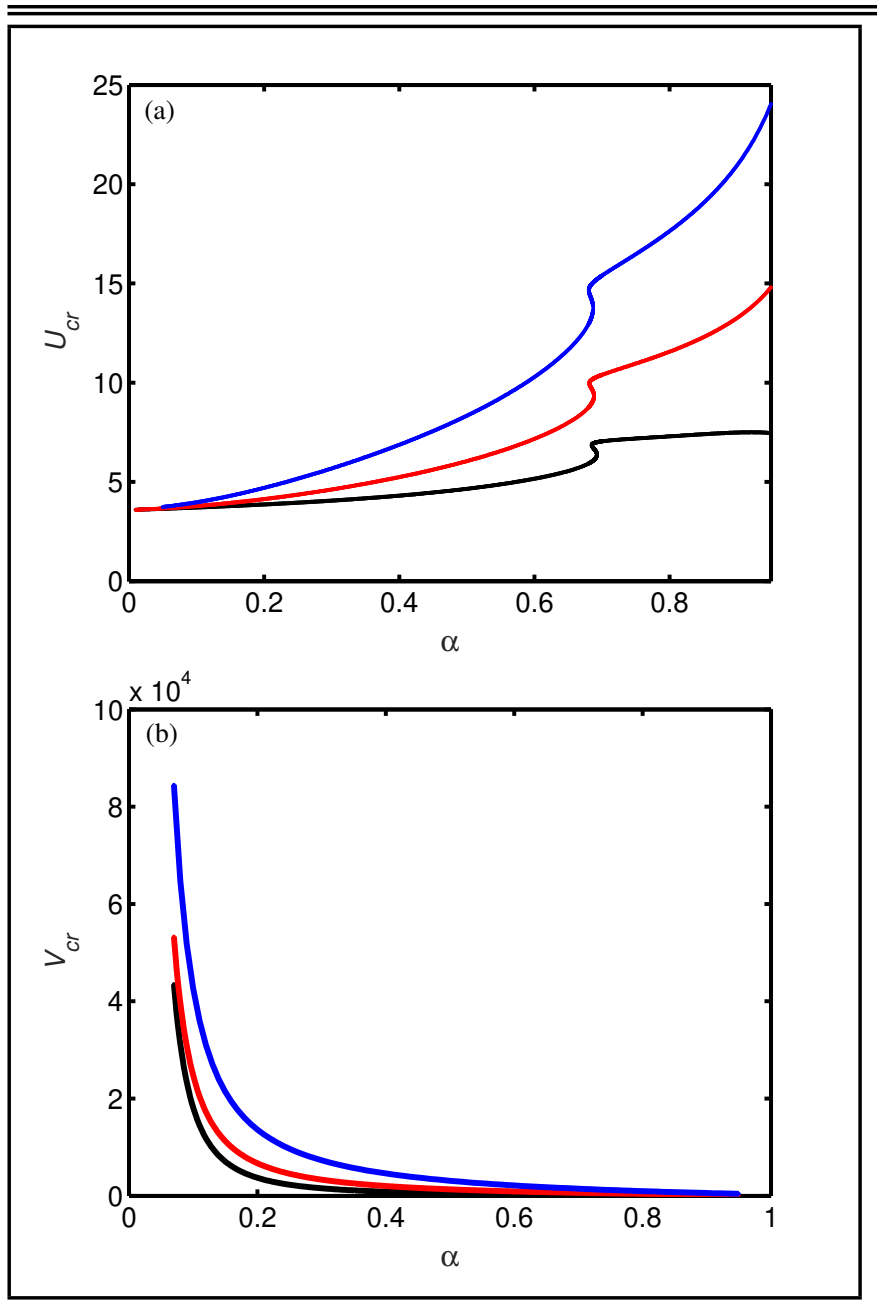

Figure 7. Flutter critical flow velocity and voltage with parameter ratio $\alpha$, black line (classical theory), red line (modified couple stress theory); blue line (modified strain gradient theory), (a) dimensionless critical flow velocity $U_{c r}$ and (b) critical voltage $V_{c r}$.

ble region under the class theory is smaller than under couple stress theory or strain gradient theory. The instability region has a considerable difference in the present parameters. However, the trend of the unstable boundary curves is consistent. The difference among flutter boundaries obtained by different theories is relatively large.

\section{CONCLUSION}

This paper introduced a cantilevered piezoelectrically actuated micropipe conveying fluid to enhance the analysis of the mechanical behavior. The modified strain gradient theory is used instead of the classical theory to build the equation of system motion and the corresponding boundary. The size effect on the stability of the system was illustrated. By employing the GDQM, the various numerical results revealed the effect of geometrical shape size, length scale parameter on critical flow velocity, and critical voltage. The main results are included as follows:

1. The influence of four boundary conditions derived from the principle on system's stability is the same.

2. The critical flow and critical voltage obtained by the modified couple stress and strain gradient theory were higher than those obtained by classical theory under the same geometric and material parameters.
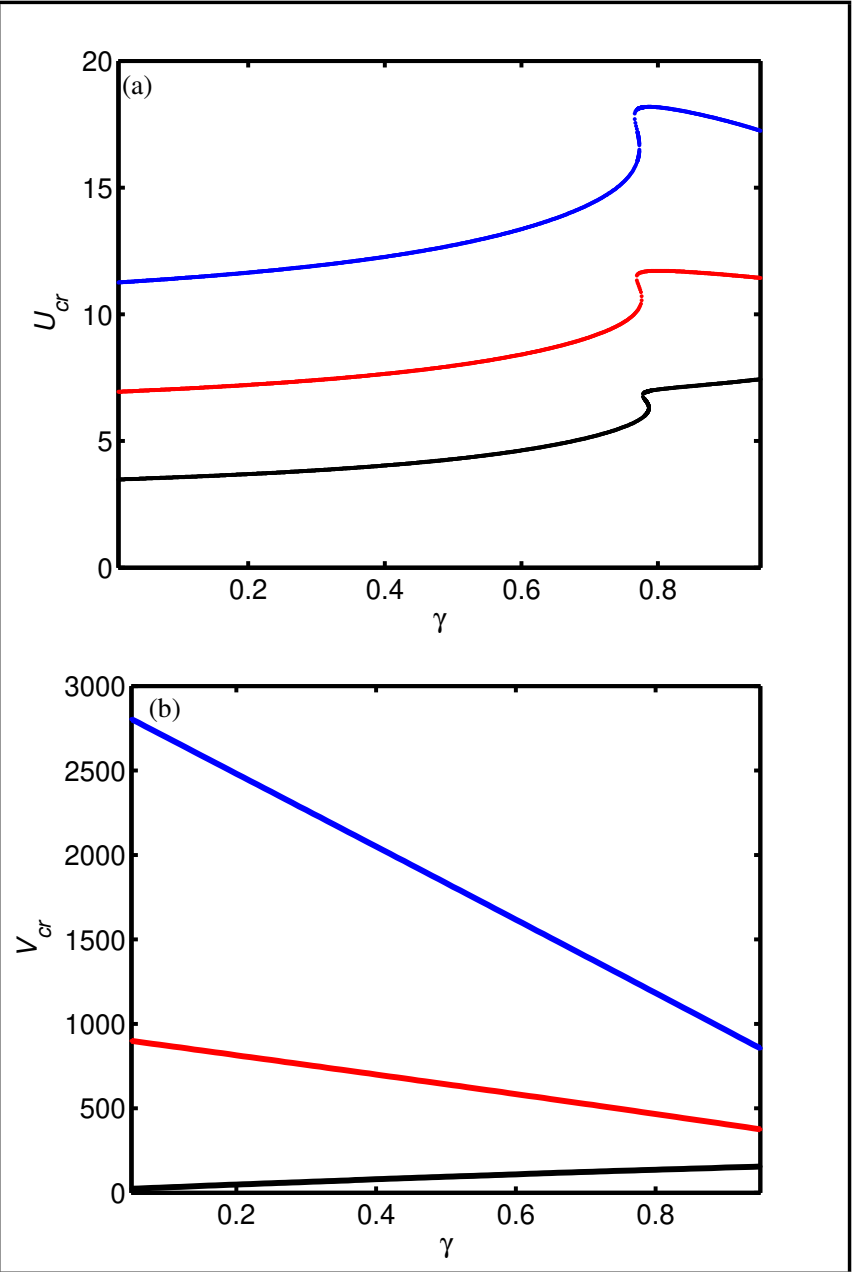

Figure 8. Flutter critical flow velocity and voltage concerning parameter ratio $\gamma$, (a)dimensionless critical flow velocity $U_{c r}$ and (b) critical voltage $V_{c r}$.

3. Various geometric and scale parameters had an important influence on the critical flow velocity and voltage of the system. The height $h_{\text {out }}$ of the outer rectangle section changes with the parameter $\alpha$ when the $h_{\text {in }}$ of the inner rectangle section is unchangeable. The critical flow velocity $U_{c r}$ increases with the parameter $\alpha$. However, the critical voltage $\mathrm{V}_{c r}$ decreased. Similarly, the parameter $\gamma$ is the ratio of the inner rectangle section width $w_{i n}$ and the outer rectangle section width $w_{\text {out }}$, the effect of which is the same with the parameter $\alpha$. The critical flow velocity and voltage also increased with the size-dependent effect $\ell$.

The authors need point out that the current dynamic model was created without considering geometric nonlinearity. However, this paper focused on the stable analysis of the system, and it was reasonable to adopt the current model. A further discussion about the nonlinear post-instability behavior of the cantilever can be found in the author's follow-up articles.

\section{ACKNOWLEDGEMENT}

The research was partially supported by the National Natural Science Foundation of China (GrantNumbers11872043), and the Opening Project of Sichuan Province University Key Laboratory of Bridge Non-destruction Detecting and Engineering Computing (GrantNumbers2016QZJ03), and Fund Project of Sichuan University of Science and Engineering in hit-haunting 


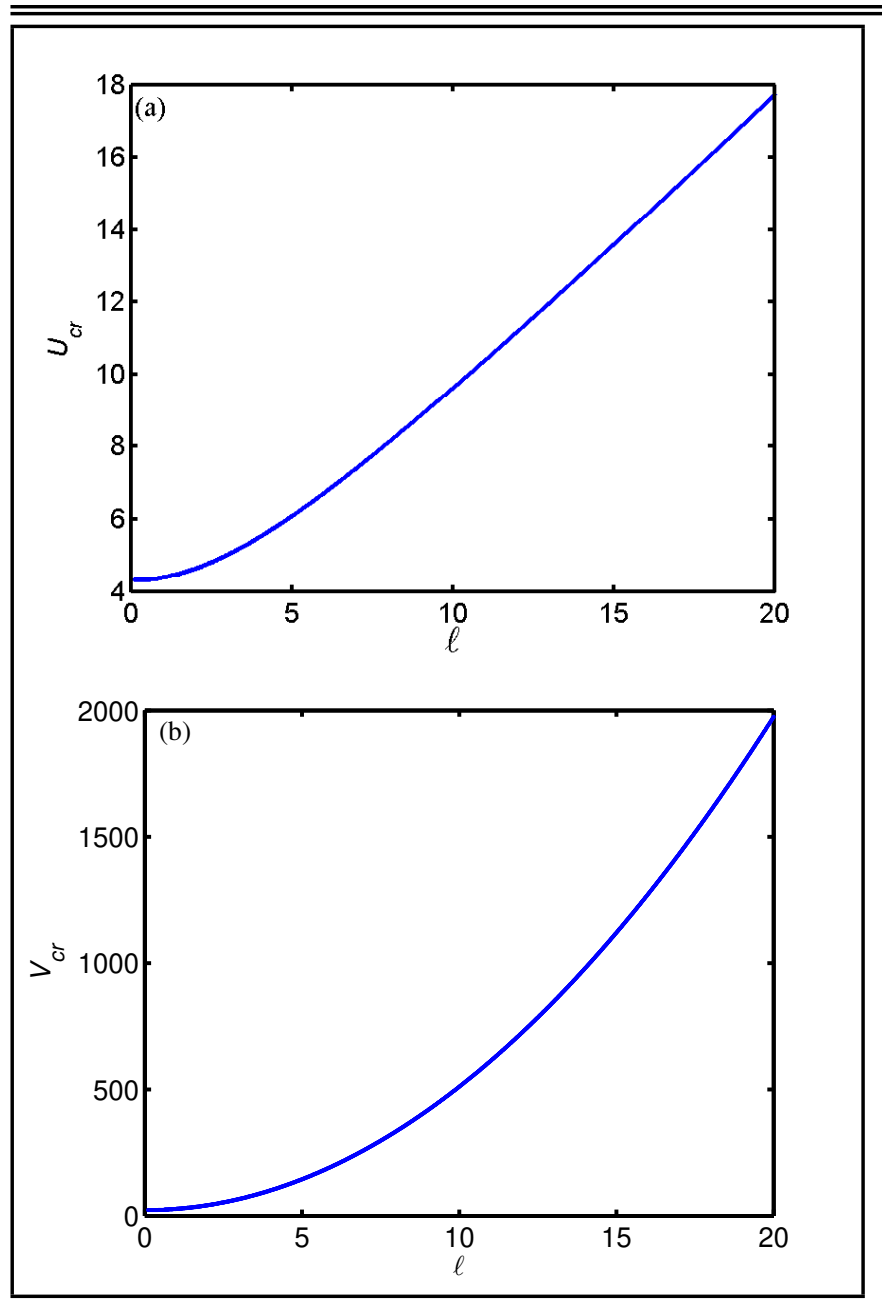

Figure 9. Flutter critical flow velocity and voltage of as size-dependent effect $\ell$ (a)dimensionless critical flow velocity $U_{c r}$ and (b) critical voltage $V_{c r}$.

for talents (GrantNumbers2016RCL31 and 2018RCL11), and Key projects of Department of Education of Sichuan Province (GrantNumbers18ZA0353), and Zigong Science and Technology Program(GrantNumbers2020YGJC03). The authors thank the anonymous reviewers for their helpful suggestions.

\section{REFERENCES}

1 Paidoussis, M. P. Fluid-structure interactions: slender structures and axial flow, Vol. 1, Elsevier Academic Press, London, (1998).

2 Ibrahim, R. Overview of mechanics of pipes conveying fluids,part I: Fundamental studies, Journal of Pressure Vessel Technology, 132(3), 034001:1-32, (2010). https://dx.doi.org/10.1115/1.4001271

3 Kim, K.-H. Moldovan, N. and Espinosa, H. D. A nanofountain probe with sub-100 nm molecular writing resolution, Small, 1(6), 632-635,(2005). https://dx.doi.org/10.1115/1.4001271

4 Pagona, G. and Tagmatarchis, N. Carbon nanotubes: materials for medicinal chemistry and biotechnological applications, Current medicinal chemistry, 13(15), 1789-1798, (2006). https://dx.doi.org/10.2174/092986706777452524

5 Longhurst,M. and Quirke, N. Temperature-driven pumping of fluid through single-walled carbon

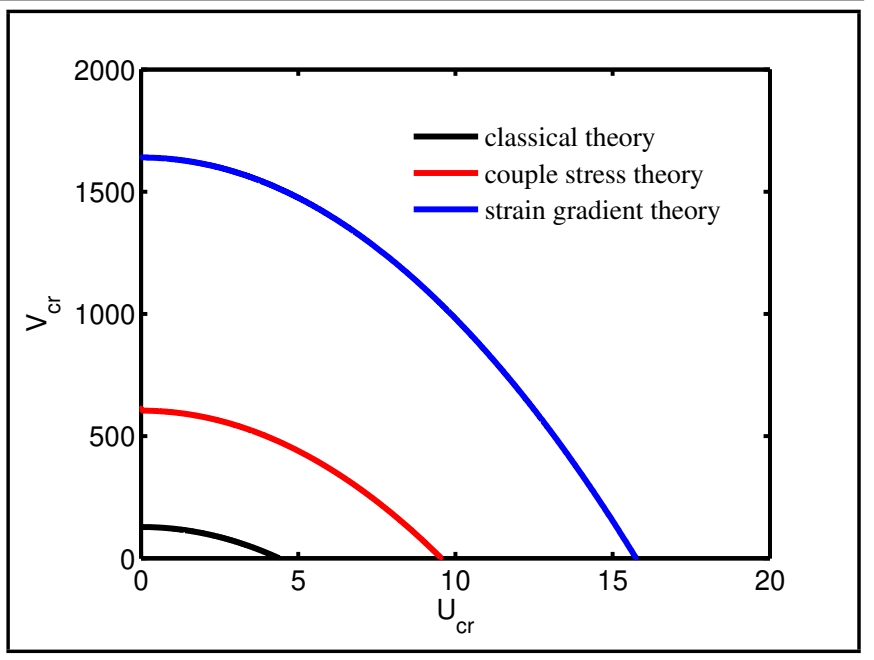

Figure 10. Flutter critical flow velocity $U_{c r}$ and voltage $V_{c r}$ in different elastic theory.

nanotubes, Nano letter, 7(11), 3324-3328, (2007). https://dx.doi.org/10.1021/n1071537e

6 Lam, D., Yang, F., Chong, A., Wang, J., and Tong, P. Experiments and theory in strain gradient elasticity, Journal of the Mechanics \& Physics of Solids, 51(8), 1477-1508, (2003). https://dx.doi.org/10.1016/S0022-5096(03)00053-X

7 Tang, C. and Alici, G. Evaluation of length-scale effects for mechanical behaviour of micro- and nanocantilevers: I. Experimental determination of length-scale factors, Journal of Physics D: Applied Physics, 44(33), 335501, (2011). https://dx.doi.org/10.1088/0022-3727/44/33/335501

8 Tang, C. and Alici, G. Evaluation of length-scale effects for mechanical behaviour of micro- and nanocantilevers: II. Experimental verification of deflection models using atomic force microscopy, Journal of Physics D: Applied Physics, 44(33), 335502, (2011). https://dx.doi.org/10.1088/0022$3727 / 44 / 33 / 335502$

9 Dehrouyeh-Semnani, A. M. A discussion on different nonclassical constitutive models of microbeam, International Journal of Engineering Science, 85(11), 66-73, (2014). https://dx.doi.org/10.1016/j.ijengsci.2014.07.008

10 Liebold, C. and Mller, w. Comparison of gradient elasticity models for the bending of micromaterials, Computational Materials Science, 116, 52-61, (2016). https://dx.doi.org/10.1016/j.commatsci.2015.10.031

11 Lei, J., He, Y., Guo,S. Li, Z.and Liu, D. Size-dependent vibration of nickel cantilever microbeams: Experiment and gradient elasticity, Aip Advances, 6(10), 51-59, (2016). https://dx.doi.org/10.1063/1.4964660

12 Li, Z., He, Y., Lei, J.,Han, S., Guo, S. and Liu.,D. Experimental investigation on size-dependent highermode vibration of cantilever microbeams, $\mathrm{Mi}$ crosystem Technologies, 25(8), 30050-3015, (2019). https://dx.doi.org/10.1007/s00542-018-4244-0

$13 \mathrm{Wi}$, D.and Sodemann, A. Investigation of the size effect on the resonant behavior of mesoscale cantilever beams, Journal of Vibration and Control, 25(23-24), 2946-2955, (2019). https://dx.doi.org/10.1177/1077546319872311 
$14 \mathrm{Wu}, \mathrm{Q}$. and Qi, G., Quantum dynamics for al-doped graphene composite sheet under hydrogen atom impact, Applied Mathematical Modelling, 90, 1120-1129, (2021). https://dx.doi.org/10.1016/j.apm.2020.10.025

15 Wu,Q., Yao, M., Li, M., Cao, D. and Bai, B. Nonlinear coupling vibrations of graphene composite laminated sheets impacted by particles, Applied Mathematical Modelling, 93, 75-88, (2021). https://dx.doi.org/10.1016/j.apm.2020.12.008

16 Rinaldi, S., Prabhakar, S., Vengallatore, S. and Pardoussis, M. P. Dynamics of microscale pipes containing internal fluid flow: Damping, frequency shift, and stability, Journal of Sound and Vibration, 329 (8), 1081-1088, (2010). https://dx.doi.org/10.1016/j.jsv.2009.10.025

17 Wang, L. Size-dependent vibration characteristics of fluid-conveying microtubes, Journal of Fluids and Structures, 26(4), 675-684, (2010). https://dx.doi.org/10.1016/j.jfluidstructs.2010.02.005

18 Xia, W. and Wang, L. Microfluid-induced vibration and stability of structures modeled as microscale pipes conveying fluid based on non-classical timoshenko beam theory, Microfluidics and nanofluidics, 9(45), 955-962, (2010). https://dx.doi.org/10.1007/s10404-010-0618-z

19 Yin, L., Qian, Q. and Wang, L. Strain gradient beam model for dynamics of microscale pipes conveying fluid, Applied Mathematical Modelling, 35(6), 2864-2873, (2011). https://dx.doi.org/10.1016/j.apm.2010.11.069

20 Yang,T.-Z., Ji, S., Yang, X.-D. and Fang, B. Microfluidinduced nonlinear free vibration of microtubes, International Journal of Engineering Science, 76, 47-55, (2014). https://dx.doi.org/10.1016/j.ijengsci.2013.11.014

21 Hosseini, M. and Bahaadini, R., Size dependent stability analysis of cantilever micro-pipes conveying fluid based on modified strain gradient theory, International Journal of Engineering Science, 101, 1-13, (2016). https://dx.doi.org/10.1016/j.ijengsci.2015.12.012

22 Deng, J., Liu, Y. and Liu, W. Size-dependent vibration analysis of multi-span functionally graded material micropipes conveying fluid using a hybrid method, Microfluidics and nanofluidics, 21(8), 1-15, (2017). https://dx.doi.org/10.1007/s10404-017-1967-7

23 M. Ghazavi, H. Molki, et al., Nonlinear vibration and stability analysis of the curved microtube conveying fluid as a model of the micro coriolis flowmeters based on strain gradient theory, Applied Mathematical Modelling, 45, 1020-1030, (2017). https://dx.doi.org/10.1016/j.apm.2017.01.048

24 Rezazadeh, G., Tahmasebi, A. and Zubstov, M. Application of piezoelectric layers in electrostatic mem actuators: controlling of pull-in voltage, $\mathrm{Mi}$ crosystem technologies, 12(12), 1163-1170, (2006). https://dx.doi.org/10.1007/s00542-006-0245-5
25 Abbasnejad, B., Shabani, R.and Rezazadeh, G. Stability analysis of a piezoelectrically actuated micropipe conveying fluid, Microfluidics and Nanofluidics, 19(3), 577-584, (2015). https://dx.doi.org/10.1007/s10404-015-1584-2

26 Hosseini, M., Maryam, A. Z. B. and Bahaadini, R. Forced vibrations of fluid-conveyed double piezoelectric functionally graded micropipes subjected to moving load, Microfluidics and Nanofluidics, 21(8), 134, (2017). https://dx.doi.org/10.1007/s10404-017-1963-y

27 Hosseini, M., Bahaadini, R. and Jamali, B. Nonlocal instability of cantilever piezoelectric carbon nanotubes by considering surface effects subjected to axial flow, Journal of Vibration and Control, 24(9), 1809-1825, (2018). https://dx.doi.org/10.1177/1077546316669063

28 Rezazadeh, G., Fathalilou, M. and Shabani, R. Static and dynamic stabilities of a microbeam actuated by a piezoelectric voltage, Microsystem Technologies, 15(12), 1785, (2009). https://dx.doi.org/10.1007/s00542-009-0917-z

29 Lam, D. C., Yang, F., Chong, A., Wang, J. and Tong, P. Experiments and theory in strain gradient elasticity, Journal of the Mechanics and Physics of Solids, 51(8), 1477-1508, (2003). https://dx.doi.org/10.1016/S0022-5096(03)00053$\mathrm{X}$

30 Wang, L., Liu, H. T., Ni, Q. and Wu,Y. Flexural vibrations of microscale pipes conveying fluid by considering the size effects of micro-flow and microstructure, Inational Journal of Engineering Science,71(10), 92-101, (2013). https://dx.doi.org/10.1016/j.ijengsci.2013.06.006

31 Dai, H. L., Wang, L. and Ni,Q. Dynamics and pull-in instability of electrostatically actuated microbeams conveying fluid, Microfluidics and Nanofluidics, 18(1), 49-55, (2015). https://dx.doi.org/10.1007/s10404-014-1407-x

32 Bruus, H. Theoretical Microfluidics, Oxford university press, Oxford, 2008.

33 Du, H., Lim,M. and Lin, R. Application of generalized differential quadrature method to structural problems, International Journal for Numerical Methods in Engineering, 37(11), 1881-1896, (1994). https://dx.doi.org/10.1002/nme.1620371107

$34 \mathrm{Wu}, \mathrm{T}$. and Liu, G. Application of generalized differential quadrature rule to sixth-order differential equations, Communications in Numerical Methods in Engineering, 16(11), 777-784, (2000).

https://dx.doi.org/10.1002/10990887(200011)16:11<777::AID-CNM375>3.0.CO;2-6

35 Naschie, M. Stress, Stability, Chaos in Structural Engineering: An Energy Approach, McGraw Hill, London, (1990). 